\title{
D-galactose supplementation in individuals with PMM2-CDG: results of a multicenter, open label, prospective pilot clinical trial
}

Peter Witters ${ }^{1,2^{*}}$, Hans Andersson ${ }^{3}$, Jaak Jaeken', Laura Tseng ${ }^{4}$, Clara D. M. van Karnebeek ${ }^{5,6}$, Dirk J. Lefeber ${ }^{7}$, David Cassiman ${ }^{8}$ and Eva Morava ${ }^{1,9}$

\begin{abstract}
PMM2-CDG is the most prevalent congenital disorder of glycosylation (CDG) with only symptomatic therapy. Some CDG have been successfully treated with D-galactose. We performed an open-label pilot trial with D-galactose in 9 PMM2-CDG patients. Overall, there was no significant improvement but some milder patients did show positive clinical changes; also there was a trend toward improved glycosylation. Larger placebo-controlled studies are required to determine whether D-galactose could be used as supportive treatment in PMM2-CDG patients.

Trial registration ClinicalTrials.gov Identifier: NCT02955264. Registered 4 November 2016, https://clinicaltrials.gov/ct2/ show/NCT02955264
\end{abstract}

Keyword: PMM2-CDG, D-galactose, Glycosylation, Congenital disorder of glycosylation (CDG), Nijmegen pediatric CDG rating scale (NPCRS)

\section{Introduction}

Phosphomannomutase 2-congenital disorder of glycosylation (PMM2-CDG; OMIM: 601,785) is the most common CDG, with more than 1000 reported patients. This multi-system disease typically presents with neurological involvement (intellectual disability, hypotonia, muscle weakness, neuropathy and ataxia) in combination with liver involvement, endocrine disturbances (hypothyroidism, growth failure, hypogonadotropic hypogonadism, hypoglycemia), clotting factor abnormalities (disturbed hemostatic balance of both pro- and anticoagulants), gastrointestinal disease, etc. [1]. There is $20 \%$ mortality observed in the first four years followed by a relatively stable disease course [2]. Currently, only symptomatic or supportive therapy is available [3-5].

*Correspondence: Peter.witters@uzleuven.be

${ }^{1}$ Metabolic Center, Department of Pediatrics, University Hospitals Leuven, Herestraat 49, 3000 Leuven, Belgium

Full list of author information is available at the end of the article
Nutritional intervention with oral $\mathrm{D}$-galactose (D-gal) has shown beneficial effects in certain CDG, associated with abnormal glycosylation and hypogalactosylation. Oral D-gal supplementation showed biochemical and clinical benefit in TMEM165-CDG, SLC35A2-CDG and SLC39A8-CDG [4-6]. In addition, a CDG caused by biallelic pathogenic variants in $P G M 1$ is highly responsive to D-gal $[7,8]$. As galactose is known to increase nucleotide sugar levels, specifically UDP-galactose and UDPglucose, in vitro in fibroblasts derived from individuals with and without CDG. [7], we hypothesized that D-gal supplementation and increasing the UDP-hexose pool, could be of benefit in CDG, even without a clear galactosylation defect. Previously, in vitro studies have shown that several different CDG type I cell lines increase glycosylated ICAM1 expression under galactose treatment, including a few cell lines of PMM2-CDG patients. Additionally, galactose also regulates the activity of different galactosyltransferases [6], and galactose could act as a chaperone, similar to its use in Fabry disease [9], as with original author(s) and the source, provide a link to the Creative Commons licence, and indicate if changes were made. The images or other third party material in this article are included in the article's Creative Commons licence, unless indicated otherwise in a credit line to the material. If material is not included in the article's Creative Commons licence and your intended use is not permitted by statutory regulation or exceeds the permitted use, you will need to obtain permission directly from the copyright holder. To view a copy of this licence, visit http://creativecommons.org/licenses/by/4.0/. The Creative Commons Public Domain Dedication waiver (http://creativeco mmons.org/publicdomain/zero/1.0/) applies to the data made available in this article, unless otherwise stated in a credit line to the data. 
enzymes with sugar substrates, sugars often funciton as chaperones.

We performed an observational prospective multicenter pilot study and evaluated the clinical and biochemical evolution of 9 patients with PMM2-CDG, taking oral D-gal supplementation for an 18-week period. The study was open label and without placebo control.

\section{Patients and methods}

\section{Galactose and nijmegen pediatric CDG rating scale} (NPCRS)

Participants were evaluated at three clinical sites using the same observational protocol (Tulane University Medical Center, University of Leuven and Amsterdam University Medical Centers) as part of an observational trial (Tulane IRB protocol \#517,339, ClinicalTrials.gov NCT02955264; Leuven ethics committee S59698; AMC METC NL61943.018.17). All patients were confirmed patients with PMM2-CDG based on abnormal glycosylation studies and molecular analysis (see Table 1).

D-Galactose intake was increased in a stepwise fashion over the 18 week study period per 6 weeks from $0.5 \mathrm{~g} /$ $\mathrm{kg}$ per day, to $1.0 \mathrm{~g} / \mathrm{kg}$ per day and eventually $1.5 \mathrm{~g} / \mathrm{kg}$ per day to minimize gastrointestinal and metabolic side effects. The maximum daily dose of galactose any patient received was $50 \mathrm{~g}$ (this amount is within recommended daily intake) and has been demonstrated to be safe
[10] previously in CDG patients [8]. Participants were instructed to continue their regular diet.

The Nijmegen Pediatric CDG rating scale (NPCRS) was assessed at the time of inclusion and at the end of the trial. This score comprises three sections (subscores): current clinical function, system specific involvement and current clinical assessment. A lower score indicates a less severe disease [2]. Additionally, serum sialotransferrin isoforms, as a parameter for glycosylation, were monitored. Transferrin was immunopurified from 10 $\mu \mathrm{L}$ of plasma and analyzed by QTOF mass spectrometry (MS) as previously described [11]. Results of asialo- and monosialotransferrin are expressed as percentage of disialotransferrin values.

\section{Statistics}

SPSS 22 for windows (SPSS Inc., Chicago, IL, USA) were used for statistical analysis. All results were expressed as means \pm standard deviation. For differences between repeated measurements in the same individual the Wilcoxon signed rank test was used. A p-value less than 0.05 was considered as statistically significant.

\section{Results}

Nine PMM2-CDG patients participated in this study (4 female, 5 male). Age at inclusion was $11.1 \pm 8.5$ years (for details and genetics see Table 1).

Table 1 Patient demographics and genetics

\begin{tabular}{|c|c|c|c|c|c|}
\hline & Age at start (y) & gender & Pathogenic variant 1 & Pathogenic variant 2 & $\begin{array}{l}\text { Reference (previous } \\
\text { publications with the } \\
\text { patient) }\end{array}$ \\
\hline \multirow[t]{2}{*}{1} & 6 & $\mathrm{~F}$ & p.1120C & p.G228C & PMID: 28425223 \\
\hline & & & c.359 T >C & $c .682 \mathrm{G}>\mathrm{T}$ & \\
\hline \multirow[t]{2}{*}{2} & 4 & M & p.R141H & p.P113L & PMID: 10801058 \\
\hline & & & c. $442 \mathrm{G}>\mathrm{A}$ & c. $338 \mathrm{C}>\mathrm{T}$ & \\
\hline \multirow[t]{2}{*}{3} & 5 & $\mathrm{~F}$ & p.S47L & p.Q33P & \\
\hline & & & c. $140 C>T$ & C. $98 \mathrm{~A}>\mathrm{C}$ & \\
\hline \multirow[t]{2}{*}{4} & 4 & $\mathrm{~F}$ & p.R141H & p.F183S & \\
\hline & & & c. $422 \mathrm{G}>\mathrm{A}$ & C. $548 \mathrm{~T}>\mathrm{C}$ & \\
\hline \multirow[t]{2}{*}{5} & 17 & M & p.R141H & p.F119L & PMID: 30293989 \\
\hline & & & c. $422 \mathrm{G}>\mathrm{A}$ & C. $357 C>A$ & \\
\hline \multirow[t]{2}{*}{6} & 15 & M & p.D188G & p.V231M & PMID: 30293989 \\
\hline & & & c. $563 \mathrm{~A}>\mathrm{G}$ & c. $691 G>A$ & \\
\hline \multirow[t]{2}{*}{7} & 19 & M & p.T237R & p.C241S & PMID: 30293989 \\
\hline & & & c. $710 C>G$ & c. $722 \mathrm{G}>\mathrm{C}$ & \\
\hline \multirow[t]{2}{*}{8} & 28 & $\mathrm{~F}$ & p.R141H & p.T81S & PMID: 17694350 \\
\hline & & & c. $422 \mathrm{G}>\mathrm{A}$ & $c .422 G>A$ & \\
\hline \multirow[t]{2}{*}{9} & 2 & M & p.R141H & p.F119L & \\
\hline & & & c. $422 \mathrm{G}>\mathrm{A}$ & C. $357 C>A$ & \\
\hline
\end{tabular}


Interestingly, the total NCPRS scores improved for 5 patients (see Fig. 1), but due to worsening of two patients the total score didn't show a statistically significant improvement (score before 23.9 \pm 9.6 , versus after $23.6 \pm 13, p=0.44)$.There was no significant improvement in the current clinical function (NPCRS subscore 1, Fig. 1) within the total group of 9 patients (score before $8.2 \pm 4.4$, versus after $7.4 \pm 4.4$ for the whole group, where a lower score indicates improvement, $p=0.10$ ), the system specific involvement (subscore 2 before treatment $3.9 \pm 2.3$, versus after treatment $4.1 \pm 2.4, p=0.77$ ) or in the current clinical assessment (score before 11.8 \pm 4.8 , versus after $12 \pm 6.8, p=0.49$ ).

Nevertheless, in one of the patients (patient 1) significant improvement in quality of life was reported, because of less frequent infections, a growth spurt and fewer
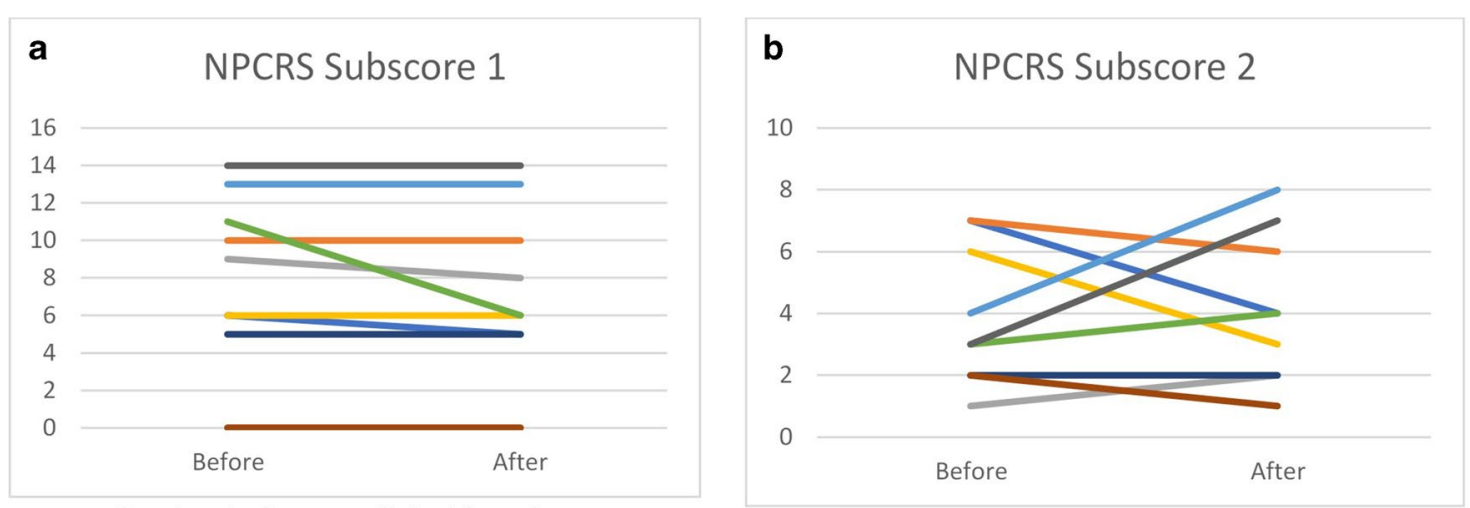

Section 1: Current clinical function

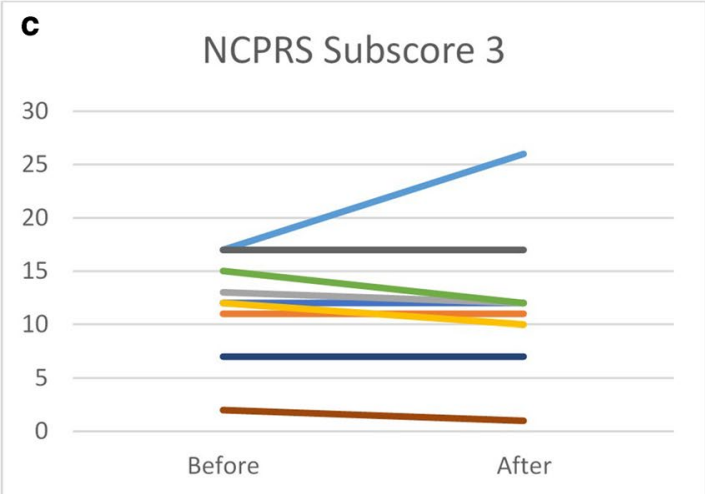

Section 3: Current clinical Assessment

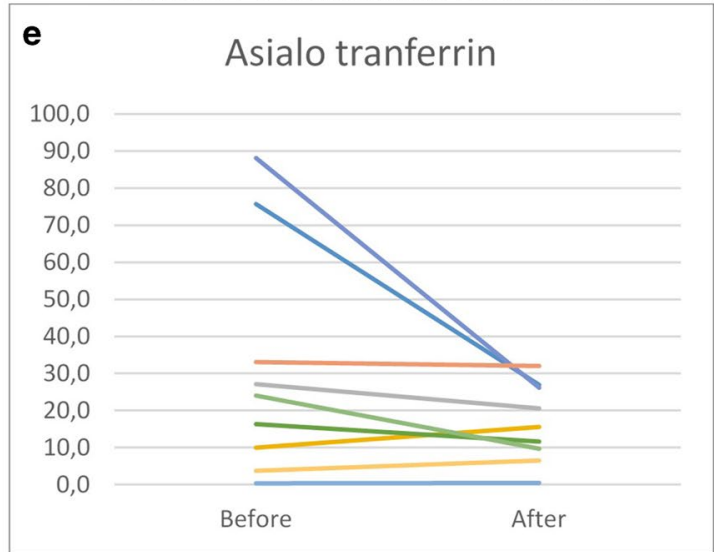

Asialotransferrin (\% of disialotransferrin)

Section 2: System specific involvement

d
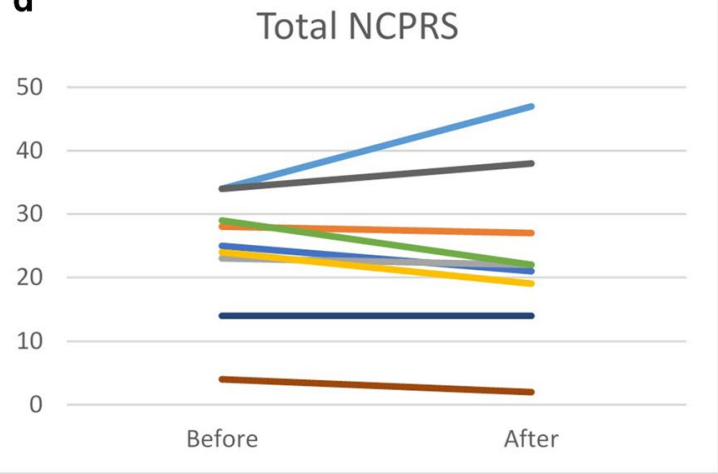

Total NCPRS

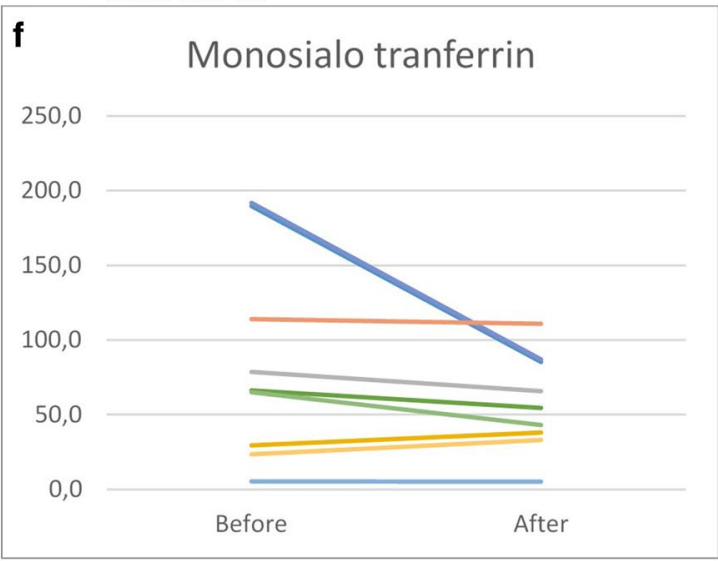

Monosialotransferrin (\% of disialotransferrin)

Fig. 1 Response to Galactose treatment. Response to escalating dose of oral D-galactose supplementation in nine patients carrying different biallelic pathogenic variants in PMM2 on the NPCRS score (a)-(d) and on glycosylation (e), (f) 
episodes of hypoglycemia (NPCRS decreasing from 25 to 21). This effect was noticeable after 6 weeks. Another patient (patient 4) reported a subjective improvement in motor skills, which was not effectively captured in the NPCRS score system and might be part of a more benign disease course in PMM2-CDG (NCPRS from 24 to 19).This effect was only reported at the end of the trial. Also noteworthy are the improvements of one patient (patient 8 ) with a very mild PMM2-CDG. After 6 weeks, she reported improvement in motor skills as a decrease in titubation (possibility to drink from a cup without spilling, eating soup, improved use of handheld devices, smoother speech, objectively recorded improvement in handwriting), decreased ataxia (less bumping into walls and objects) and increased general activity level. Her NPCRS decreased from 4 to 2 . Importantly, after stopping D-gal supplementation her progress reversed. Upon restarting D-gal a similar improvement was seen again.

\section{Adverse events}

There were only gastrointestinal adverse events. Six patients had mild gastrointestinal involvement (mild constipation or unexplained vomiting or diarrhea $<1 /$ week) before starting $\mathrm{D}$-gal. One patient had an increase in PMM2-CDG related diarrhea for which treatment with galactose was temporarily stopped $(<2$ weeks).Another patient had a disappearance of all gastrointestinal complaints as the constipation resolved and the polyethyleneglycol preparation was stopped.

\section{Biochemical variation}

As analyzed over the group of 9 patients, the asialotransferrin/disialotransferrin ratio improved from $30.9 \pm 31$ to $16.6 \pm 10.5$, which was however not statistically significant $(p=0.11)$. Nevertheless, there was a trend for improvement in monosialotransferrin/disialotransferrin ratio from $84.9 \pm 68.2$ to $58.1 \pm 32.6(p=0.06)$.

There was no apparent correlation of the overall biochemical trend with clinical improvements in individual patients.

\section{Discussion}

Overall, in the whole group of nine PMM2-CDG patients there was no statistically significant improvement observed with oral D-gal supplementation. When evaluated as a group, there was no biochemical improvement in the glycosylation profile or detectable clinical improvement in the different sections. Our two patients with the highest NCPRS did not respond at all. Both had profound central nervous system involvement with pyramidal signs. This is probably related to the role of glycosylation in brain development and is as such unlikely to respond to improvement in glycosylation.
Importantly, a few patients did report improvement in different aspects of their clinical symptoms and the mildest patient has experienced objectively measurable clinical changes in neurologic symptoms. Although none of these improvements were captured in a multi-item score as the NPCRS, this did lead to a significant increase in the quality of life of this patient. NCPRS certainly lacks sensitivity in some domains (for example, evolution in writing skills, titubation, decrease in number of infections etc.) as seen in some patients. Nevertheless, in our retrospective natural history study NCPRS has been shown to be stable in untreated patients [2]. Prospective natural history studies are currently being conducted.

D-gal supplementation is safe in numerous CDG [6-8] and in focal segmental glomerulosclerosis [10]. It is interesting to note that in a population with a multisystem disease in which gastrointestinal disease (constipation, diarrhea, failure to thrive, protein losing enteropathy [2, 3]) is an important part, galactose is clinically well tolerated. Indeed, there was no deterioration in GI function as measured by NPCRS.

Larger placebo-controlled, double blind studies are required to determine whether $\mathrm{D}$-gal supplementation can be used as symptomatic treatment in a subset of milder PMM2-CDG patients. Given the lack of reliable, prospectively evaluated biomarkers, clinical findings (such as NCPRS) and CDG validated quality of life outcome measures are preferable outcome measures.

\section{Abbreviations}

CDG: Congenital disorder of glycosylation; PMM2-CDG: Phosphomannomutase2-congenital disorder of glycosylation; D-gal: D-galactose; NPCRS: Nijmegen Pediatric CDG rating scale; MS: Mass spectrometry.

\section{Acknowledgements}

This work is partially funded by the grant titled Frontiers in Congenital Disorders of Glycosylation (1U54NS115198-01) from the National Institute of Neurological Diseases and Stroke (NINDS) and the National Center for Advancing Translational Sciences (NCATS) and the Rare Disorders Consortium Research Network (RDCRN). This work was partially funded by FWO Flanders, Belgium (G049220N). P.W., J.J. and D.C. are members of the European Reference Network for Rare Hereditary Metabolic Disorders (MetabERN)_Project ID No 739543. P.W. is supported by the clinical research fund, University Hospitals Leuven, Leuven, Belgium. D.C. is a recipient of the clinical investigatorship, FWO Flanders, Belgium.

\section{Authors' contributions}

All authors read and approved the final manuscript and have made substantial contributions to the work, including interpretation of the data. Further contributions are: Paitent inclusion: PW, HA, JJ, LT, CV, DC, EM. Biochemical acquisition analysis: JJ, DL. Clinical acquisition analysis: PW, DC, EM. Design and conception EM. Drafting of the work: PW, EM, CV, DC, DL. All authors read and approved the final manuscript.

\section{Funding}

This work is partially funded by the grant titled Frontiers in Congenital Disorders of Glycosylation (1U54NS115198-01) from the National Institute of Neurological Diseases and Stroke (NINDS) and the National Center for Advancing Translational Sciences (NCATS) and the Rare Disorders Consortium Research Network (RDCRN). This work was partially funded by FWO Flanders, 
Belgium (G049220N). P.W. is supported by the clinical research fund, University Hospitals Leuven, Leuven, Belgium. D.C. is a recipient of the clinical investigatorship, FWO Flanders, Belgium.

\section{Availability of data and materials}

All generated data is available within the manuscript.

\section{Ethics approval and consent to participate:}

Participants were evaluated at three clinical sites using the same observational protocol (Tulane University Medical Center, University of Leuven and Amsterdam University Medical Centers) as part of an observational trial (Tulane IRB protocol \#517339, ClinicalTrials.gov NCT02955264; Leuven ethics committee S59698; AMC METC NL61943.018.17).

\section{Consent for publication}

Current article does not contain individual data (as a case report), images or videos. There is no identifiable information submitted. This has been overseen by the ethical committee. Current work is in agreement with GDPR and HIPAA regulations.

\section{Competing interests}

The authors declare that they have no competing interests.

\section{Author details}

${ }^{1}$ Metabolic Center, Department of Pediatrics, University Hospitals Leuven, Herestraat 49, 3000 Leuven, Belgium. ${ }^{2}$ Department of Development and Regeneration, KU Leuven, Leuven, Belgium. ${ }^{3}$ Hayward Genetics Center, Tulane University School of Medicine, New Orleans, LA, USA. ${ }^{4}$ Departments of Pediatrics, Emma Children's Hospital, Amsterdam, The Netherlands. ${ }^{5}$ Departments of Pediatrics, Emma Children's Hospital, Amsterdam University Medical Centers, Amsterdam, The Netherlands. ${ }^{6}$ Department of Pediatrics, Radboud Centre for Mitochondrial Medicine, Radboud University Medical Centre, Nijmegen, The Netherlands. ${ }^{7}$ Department of Neurology, Translational Metabolic Laboratory, Donders Institute for Brain, Cognition, and Behavior, Radboudumc, Nijmegen, The Netherlands. ${ }^{8}$ Metabolic Center, University Hospitals Leuven, Leuven, Belgium. ${ }^{9}$ Department of Clinical Genomics, Mayo Clinic, Rochester, USA.

Received: 27 August 2020 Accepted: 9 November 2020 Published online: 20 March 2021

\section{References:}

1. Ferreira CR, Altassan R, Marques-Da-Silva D, Francisco R, Jaeken J, Morava E. Recognizable phenotypes in CDG. J Inherit Metab Dis. 2018;41:541-53.

2. Witters P, Honzik T, Bauchart E, Altassan R, Pascreau T, Bruneel A, et al. Long-term follow-up in PMM2-CDG: are we ready to start treatment trials? Genet Med. 2018

3. Altassan R, Péanne R, Jaeken J, Barone R, Bidet M, Borgel D, et al. International clinical guidelines for the management of phosphomannomutase 2-congenital disorders of glycosylation: diagnosis, treatment and follow up. J Inherit Metab Dis. 2019;42:5-28.

4. Witters $P$, Cassiman D, Morava E. Nutritional therapies in congenital disorders of glycosylation (CDG). Nutrients. 2017;9.

5. Verheijen J, Tahata S, Kozicz T, Witters P, Morava E. Therapeutic approaches in congenital disorders of glycosylation (CDG) involving N-linked glycosylation: an update. Genet Med. 2020;22:268-79.

6. Morelle W, Potelle S, Witters P, Wong S, Climer L, Lupashin V, et al. Galactose supplementation in patients With TMEM165-CDG rescues the glycosylation defects. J Clin Endocrinol Metab. 2017;102:1375-86.

7. Radenkovic S, Bird MJ, Emmerzaal TL, Wong SY, Felgueira C, Stiers KM, et al. The metabolic map into the pathomechanism and treatment of PGM1-CDG. Am J Hum Genet. 2019;104:835-46.

8. Wong SY-W, Gadomski T, van Scherpenzeel M, Honzik T, Hansikova H, Holmefjord KSB, et al. Oral D-galactose supplementation in PGM1-CDG. Genet Med. 2017;19:1226-35.

9. Frustaci A, Chimenti C, Ricci R, Natale L, Russo MA, Pieroni M, et al. Improvement in cardiac function in the cardiac variant of Fabry's disease with galactose-infusion therapy. N Engl J Med. 2001;345:25-32.

10. De Smet E, Rioux J-P, Ammann H, Déziel C, Quérin S. FSGS permeability factor-associated nephrotic syndrome: remission after oral galactose therapy. Nephrol Dial Transplant. 2009;24:2938-40.

11. van Scherpenzeel M, Steenbergen G, Morava E, Wevers RA, Lefeber DJ. High-resolution mass spectrometry glycoprofiling of intact transferrin for diagnosis and subtype identification in the congenital disorders of glycosylation. Transl Res. 2015;166(639-649):e1.

\section{Publisher's Note}

Springer Nature remains neutral with regard to jurisdictional claims in published maps and institutional affiliations.
Ready to submit your research? Choose BMC and benefit from:

- fast, convenient online submission

- thorough peer review by experienced researchers in your field

- rapid publication on acceptance

- support for research data, including large and complex data types

- gold Open Access which fosters wider collaboration and increased citations

- maximum visibility for your research: over $100 \mathrm{M}$ website views per year

At BMC, research is always in progress.

Learn more biomedcentral.com/submissions 